\title{
Review of predialysis education programs: a need for standardization
}

\author{
This article was published in the following Dove Press journal: \\ Patient Preference and Adherence \\ 9 September 2015 \\ Number of times this article has been viewed
}

\author{
Judith Van den Bosch' \\ D Simone Warren' \\ Peter A Rutherford ${ }^{2}$ \\ 'Pallas Health Research and \\ Consultancy BV, Rotterdam, the \\ Netherlands; ${ }^{2}$ Baxter Healthcare SA, \\ Zürich, Switzerland
}

\begin{abstract}
To make an informed decision on renal replacement therapy, patients should receive education about dialysis options in a structured program covering all modalities. Many patients do not receive such education, and there is disparity in the information they receive. This review aims to compile evidence on effective components of predialysis education programs as related to modality choice and outcomes. PubMed MEDLINE, Cochrane Library, and Ovid searches (from January 1, 1995 to December 31, 2013) with the main search terms of "predialysis", "peritoneal dialysis", "home dialysis", "education", "information", and "decision" were performed. Of the 1,005 articles returned from the initial search, 110 were given full text reviews as they potentially met inclusion criteria (for example, they included adults or predialysis patients, or the details of an education program were reported). Only 29 out of the 110 studies met inclusion criteria. Ten out of 13 studies using a comparative design, showed an increase in home dialysis choice after predialysis education. Descriptions of the educational process varied and included individual and group education, multidisciplinary intervention, and varying duration and frequency of sessions. Problem-solving group sessions seem to be an effective component for enhancing the proportion of home dialysis choice. Evidence is lacking for many components, such as timing and staff competencies. There is a need for a standardized approach to evaluate the effect of predialysis educational interventions.
\end{abstract}

Keywords: dialysis, end-stage renal disease, informed decision, modality choice

\section{Introduction}

While in-center hemodialysis (HD) remains the most common treatment modality of end-stage renal disease, home dialysis with peritoneal dialysis (PD), such as automated PD and continuous ambulatory PD, and home HD are treatment options that can provide improved clinical and patient-reported outcomes. In addition, they can be less resource intensive and costly to the health care system.

There are some clinical factors that affect whether an individual patient is clinically suited for PD, but the majority (80\%) of end-stage renal disease patients are capable of using home dialysis as their treatment. ${ }^{1}$

To date, there is no clear evidence that suggests better survival between PD and conventional three-times-per-week in-center HD, although some studies also report that PD is advantageous compared to in-center HD, with higher short-term survival rates and higher quality of life..$^{2-4}$

All renal replacement therapies have different advantages and disadvantages, which may make them more or less appropriate for the patient depending on his or her clinical and personal situation. PD, which requires learning of technical skills by the patient, also requires a degree of responsibility and capability for self-care. However, it is advantageous in allowing the patient to remain independent, and to have more control over their own treatment and lifestyle. In-center HD is performed by trained nursing
Correspondence: Peter A Rutherfor Quintiles, 500 Green Park, Reading, RG2 6UU, UK

Tel +44 II8450 I847

Email peter.rutherford@quintiles.com 
staff within a health care setting but can be inconvenient with a rigid schedule of 4 hours treatment plus travel time three times weekly. Most commonly, clinical issues do not limit the treatment selection, and patient preference should be the deciding factor in the selection of treatment modality. ${ }^{5}$

A growing body of research suggests that early referral to a nephrologist and patient education are associated with increased selection of PD among patients. When patients are presented with predialysis education clearly outlining the different treatment options, they are more likely to select a home dialysis modality. ${ }^{6}$ However, many patients do not receive predialysis education, and when they do, there is variation in what types of information they receive, ${ }^{7}$ as well as in the educational methods and system of delivery and support. As a consequence, overall rates of PD use remain much lower than those of in-center dialysis, with a global average of only approximately $11 \%$. In-center HD remains the dominant renal replacement therapy, but the rate of $\mathrm{PD}$ varies greatly between countries $^{8}$ and between centers within a country. ${ }^{9}$

The present review aims to review evidence on effective components of predialysis education programs as related to modality choice and selected clinical outcomes. This aids clinical teams in setting up educational processes to ensure patients make informed decisions.

\section{Methods}

\section{Identification and screening}

PubMed MEDLINE and Ovid databases as well as the Cochrane Library were used to search the academic literature. A tailored search string was defined in order to maximize the number of relevant results. As we were interested in articles specifically addressing the subject of predialysis education, we built the search string in a way that those terms needed to be in the title or abstract of the article: (predialysis[tiab] or pre-dialysis[tiab] or peritoneal dialysis[tiab] or home dialysis[tiab]) and (education[tiab] or information[tiab] or decision[tiab]).

To ensure data was relatively current, a limit was imposed on the search, with inclusion of studies from January 1, 1995 to December 31, 2013. A second limit was added; only papers available in English were accepted. After applying the filters, the total number of search hits returned amounted to 1,005 .

\section{Eligibility, inclusion, and exclusion}

Regarding the patient group the following inclusion criteria applied:

- Adults only ( $\geq 18$ years old)

- Predialysis education for renal replacement therapy for chronic kidney disease (CKD) patients stage III, IV, and $\mathrm{V}$
- Planned start patients, unplanned start patients, and patients on dialysis, ie, incident and prevalent patients.

With regard to the information presented on and the structure of the predialysis education programs, articles were only included if the following applied:

- A relatively detailed description of the program, such as number and content of sessions, and descriptions of educators

- Multiple sessions - a single session education was not considered a "program"

- Preferably, a duration greater than 1 month

- A multidisciplinary program involving physicians, nurses, dieticians, etc.

Regarding outcomes of the predialysis education, the scope of the literature review was broad. The following outcomes were included, if articles were available:

- Dialysis modality choice and the numbers of patients choosing each modality

- Any clinical outcome associated with predialysis education

- Health-related quality of life

- Measures associated with patient choice

- Financial impact of patients choosing more home therapies

- Patient satisfaction.

The literature was also reviewed for any information on processes, pathways, and organization of the predialysis education programs, such as:

- Patient decision making process

- Patient identification and enrolment

- Content, structure, and methodology of the predialysis education program.

Studies were excluded if the following applied:

- The study addressed practical dialysis technique training only (on PD for instance)

- Anecdotal stories on treatment option education only

- Education materials alone (ie, without process, resources, etc)

- CKD patients stage I-II;

- Patient support groups only (instead of education program)

- Too brief or unclear description of the predialysis education program.

\section{Web search}

In addition to the literature searches, a gray literature search was performed using Google. The web search was done on October 19, 2012 with the following search string: ( predialysis and [care or program or education or treatment option]). 
Searching in the first ten pages provided relevant information related to CKD educational program. Nineteen links were found to be relevant; information varied between papers, guidelines, annual reports, survey results, web information resources on CKD, web-based program descriptions, and PowerPoint presentations. ${ }^{10-28}$

Papers were excluded if they were already included in the literature search. An additional search on websites of nephrology and patient association was done. This included the following countries: Finland, Denmark, Norway, the Netherlands, UK, Canada, USA, Australia, and New Zealand. This search did not deliver data that was sufficiently detailed on the content, structure, and components of educational programs.

\section{Results \\ Relevant papers}

The literature searches yielded 29 relevant studies of which 19 had some sort of (quasi-) experimental design, ${ }^{29-47}$ and the others were mostly narrative reviews (Figure 1). ${ }^{7,48-56}$ The 19 studies were analyzed for effective components of predialysis education programs. Studies with their design and outcomes are summarized in Table 1. The Cochrane Library contained no directly relevant systematic reviews.

\section{Predialysis education and clinical outcomes Modality selection}

While no quantitative analysis was conducted, studies reported more favorable outcomes for the patients attending a predialysis education program than those patients who did not attend a predialysis education program. Of nine studies reporting on dialysis modality selection using an intervention and control group, six noted a higher proportion of patients selecting home dialysis (PD or another home modality), $30,35,38,40,41$ while three found no significant difference in modality choice..$^{29,33,36}$ Four studies with preand post- intervention (predialysis education) measurements showed higher levels of home dialysis use after the predialysis education intervention. . $^{27,32,44,45}$

\section{Patient knowledge}

Four of 19 quasi-experimental studies reported on measures of patient knowledge. All reported higher levels of knowledge

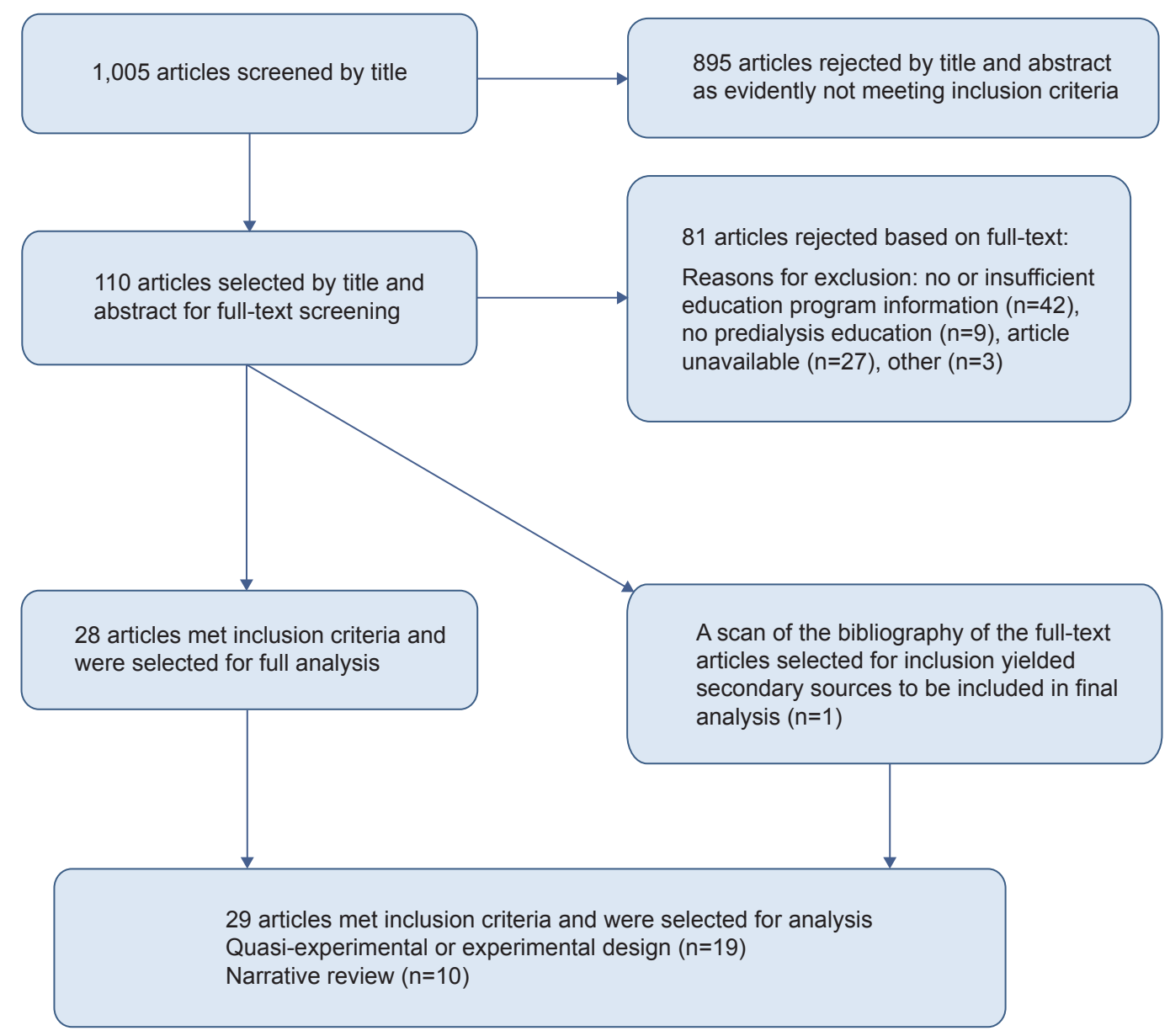

Figure I Flowchart of literature selection. 


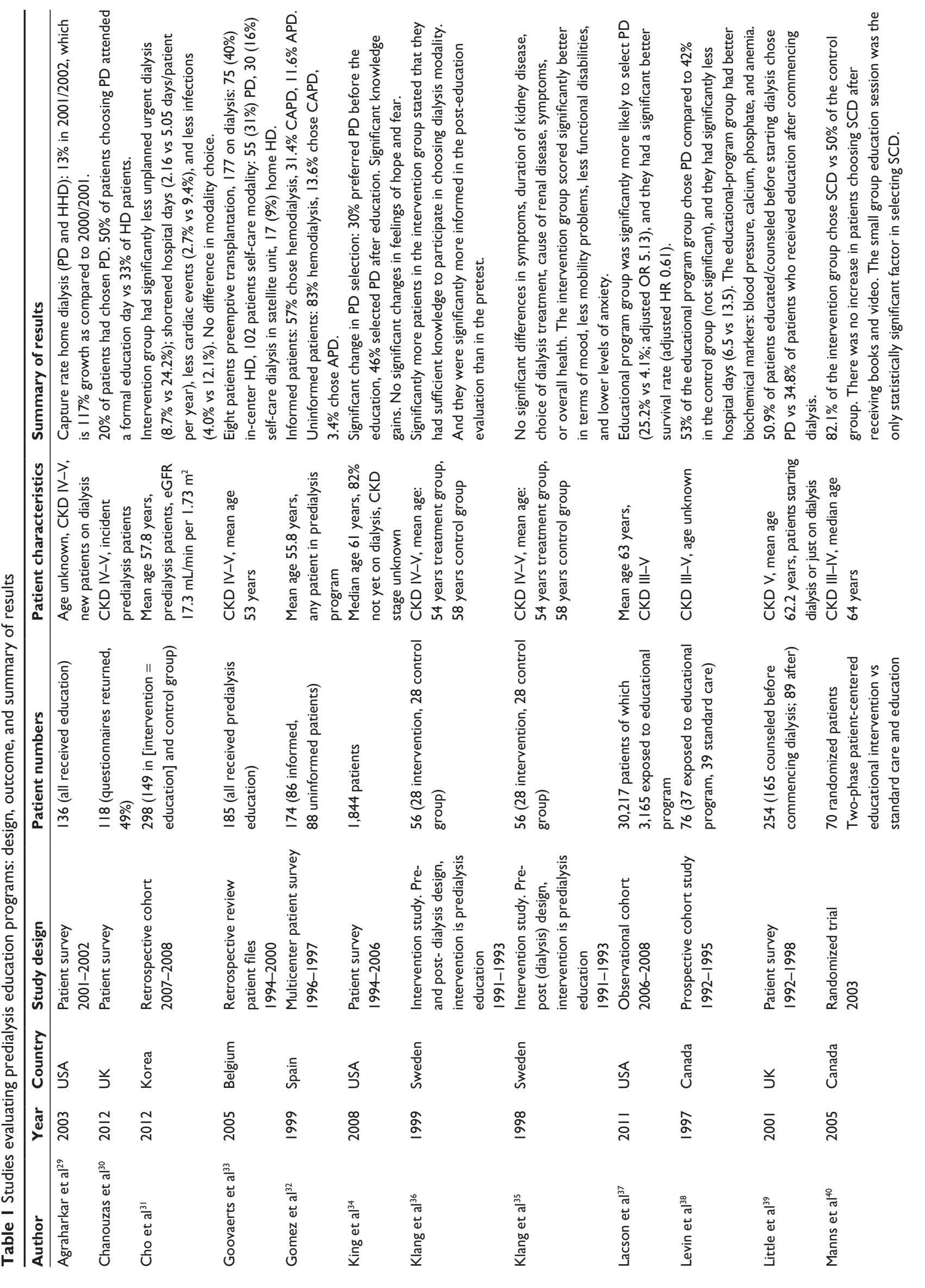




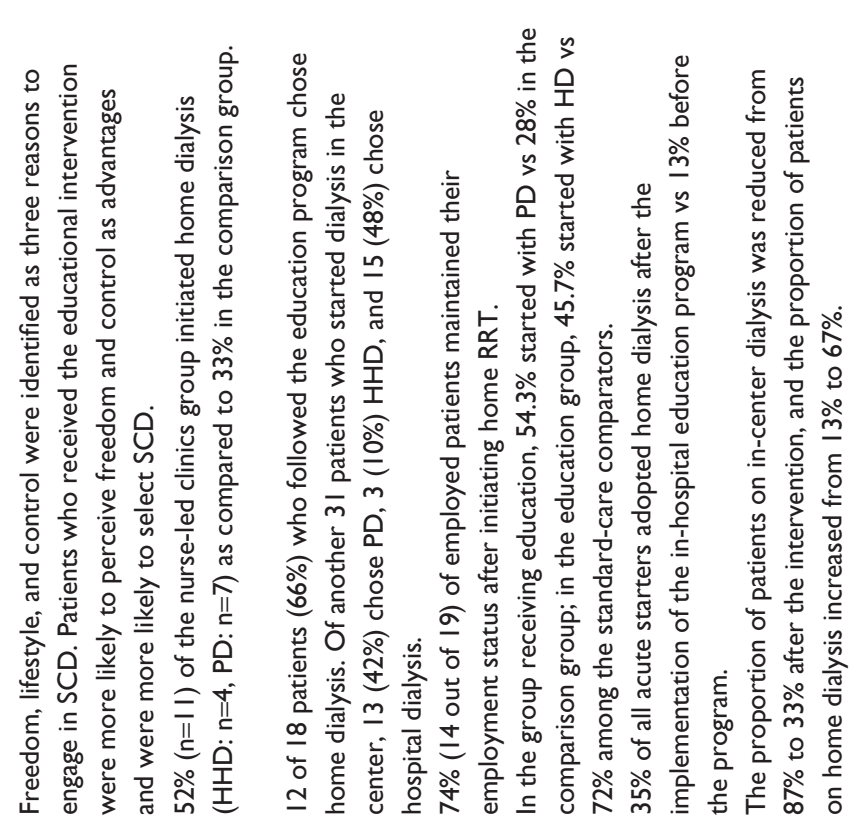

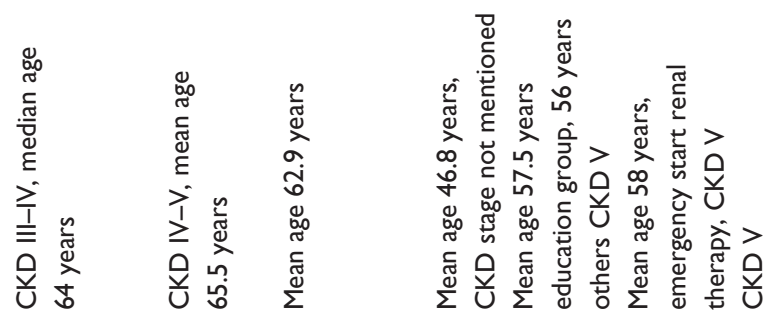
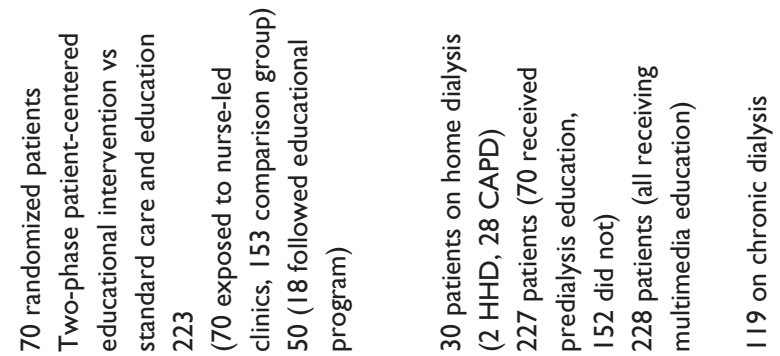

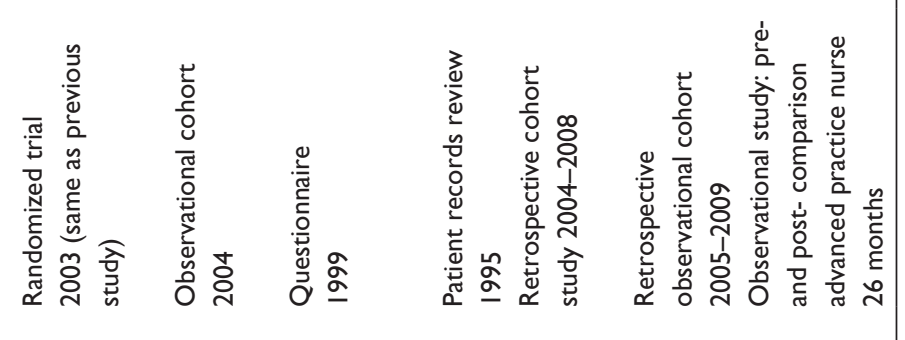

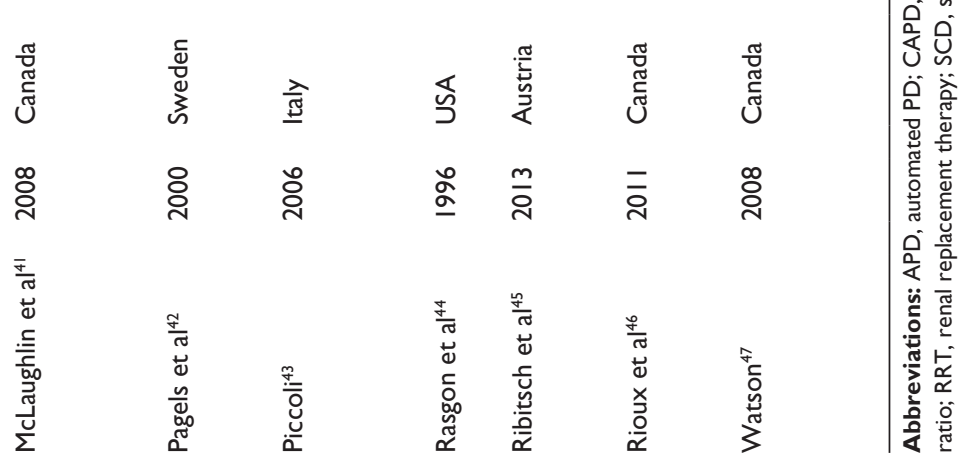


of end-stage renal disease and of different treatment options for patients receiving predialysis education. . $^{32,36,40}$

\section{Mortality and morbidity}

Two studies reported on length of hospital stay, which was lower for the education groups (6.5 versus 13.5 total hospital days; 2.2 versus 5.1 hospital days/patient per year). ${ }^{38,57}$ thus leading to cost savings. ${ }^{36}$ Eight studies reported on mortality and morbidity (including biochemical indicators, cardiovascular incidents, infection rates, emotional status). ${ }^{31,35,37,46,58,59}$ All studies reported better rates for the treatment group.

\section{Costs}

Watson ${ }^{47}$ found a reduction of in-center dialysis from $87 \%$ to $33 \%$ due to the introduction of an advanced practice nurse with an educating/counseling role. They calculated a theoretical cost saving of $\$ 1,328,000$ over a 2.5 -year period as opposed to the situation without this reduction.

\section{Components of predialysis education programs}

The articles retrieved from the literature and gray literature search addressed a wide range of aspects of predialysis education programs.

\section{Multidisciplinary education}

Predialysis care is delivered by a multidisciplinary team including, most of the time, a nephrologist, a nurse, a dietician, and a social worker. ${ }^{10,12,14,16,18,19,24,25,27,28,60}$ A multidisciplinary team can also include: a pharmacist who explains information on the medicines needs; ${ }^{21,22}$ a psychologist expert, which could be a specialized nurse for emotional support when needed; ${ }^{10,24}$ a case manager; ${ }^{25}$ representatives from the local patient kidney support group; and other patients established on maintenance dialysis. ${ }^{27}$ It is often not clear from the literature whether the members of the multidisciplinary care team are also the main educators for the patient. Of course there will be knowledge transfer during a patient's visit to a nephrologist or dietitian. It is, however, most of the time not known whether this was in the setting of an educational program with defined cognitive and functional goals.

Seven articles retrieved from the scientific literature review described multidisciplinary education program, ${ }^{29,30,35,36,40,41}$ which consists of multiple education sessions where patients are educated by three or more health care professionals such as nephrologist, nurse, dietitian, social worker, home-dialysis coordinator, pharmacist, technician, or by other dialysis patients. An Australian survey revealed that although with multidisciplinary education patients are educated by three or more health care professionals, a high proportion of the education is done by the nurse specialist, as nephrologists have limited time for one-on-one education. ${ }^{61}$ Others see an important role of the nurse as a case manager in planning, implementing, and evaluating educational programs. ${ }^{22}$

\section{Delivery style}

The education delivery style can either be one-on-one sessions or class room teaching style. But in general, a mix of one-on-one and group sessions is advocated. Educational programs should contain individualized one-on-one counseling sessions with a member/members of the multidisciplinary team. This can be a physician, nephrologist, nurse, dietician, social worker, etc..$^{39,41,55}$ In addition to those small group discussions, peer counseling and problem-solving or "brainstorming" sessions have been described wherein patients discuss treatment modalities, as well as barriers and benefits, and troubleshooting of possible problems with other patients (or facilitators). ${ }^{7,40,41}$ The group sessions can have a variety of formats such as group lectures, interactive workshops, or open forum sessions.

In the national Australian survey on predialysis education, most participating units combined group and one-on-one sessions. Group education sessions seemed to affect the choice of home dialysis; home dialysis rates increased from $20 \%$ to $38 \%$. $^{19}$

The most ideal design for investigating the effect of certain components of a predialysis education program would be a head-to-head comparison of two programs that differ in a single aspect, while patients are randomly assigned to one of the programs. There was only one study making a head-to-head comparison of two "programs"40 using randomization. In this study, standard care was compared to a group of patients who received standard care plus two-phase education. The standard care consisted of receiving teaching about kidney disease, including dietary instructions, and detailed information about the different modalities of renal replacement therapy. This occurred via an initial 3-hour one-on-one session where patients were seen by a nurse, dietician, and social worker. Patients were then followed by their nephrologist and the multidisciplinary care team every 3-6 months. The two-phase additional education consisted of phase 1 , in which patients received four written manuals and a video, and phase 2 , which consisted of a 90-minute problem solving group session. The small-group education (phase 2) turned out to be effective in enhancing the proportion of 
patients choosing self-care dialysis (including home- and self-care HD and PD) from $50 \%$ to $82 \%$.

\section{Frequency and duration}

The number of sessions and duration per session varies by educational program. There are reports of six individual sessions of 1 hour $;{ }^{14}$ four sessions, 1 night a week for 2 hours $;{ }^{27}$ or at least four to five interviews. ${ }^{10}$ Table 2 contains a description of the educational programs retrieved from the scientific literature.

In the national Australian survey, ${ }^{61}$ educators were asked to fill out how much time each new patient spends receiving information regarding treatment options. Thirteen percent of units $(n=4)$ spent on average less than 1 hour providing education. Thirteen units were educating for 1-2 hours and 13 units for over 2 hours. The rate of home dialysis was $36 \%$ in the units offering the longest education hours ( $>3$ hours) compared to $20 \%$ in the units averaging less than 1 hour's education.

\section{Timing}

Timing of education was seen as important to the patient and health care professional, but the studies did not allow firm conclusions to be reached over timing vs dialysis start. The more time a patient has to acquire knowledge prior to commencing dialysis, the better their clinical outcomes and the more likely they are to select a home dialysis modality. ${ }^{56} \mathrm{An}$ estimated glomerular filtration rate of less than $30 \mathrm{~mL} / \mathrm{min}$ (stage IV CKD) has been reported as ideal for referral to CKD clinic. ${ }^{20,21}$ Others recommend that patients should be referred as early as possible to renal education ( $>6$ months). ${ }^{19}$

\section{Learning theory}

Basing the educational program on the principles of adult learning ensures the appropriateness of delivery of educational materials and content in a manner best understood by this patient population ${ }^{33}$ and can help expedite the process of adult learning. ${ }^{7,52}$ One study ${ }^{58}$ tested a new PD home training program based on adult learning theory in a quasiexperimental prospective study using a nonstandardized conventional training group as controls. The adult-learningbased program incorporated the different domains of learning and accommodated different perceptual styles (eg, visual and auditory). The new training program improved patient outcomes (eg, less exit-site infections, less dropout to HD after infection, better fluid balance scores, and better compliance scores). Although this study focused on patients who had already chosen PD, it is a good example of the benefits of a well-designed educational program.

\section{Discussion Weak evidence base}

Unfortunately, the findings presented in the previous section are not based on a strong evidence base since there are a number of limitations found within the studies available for analysis. The study quality was often poor; experimental studies often lacked a control group, as well as pre- and postintervention measures. In some instances, data was presented in comparison to other reports or to previous findings of modality rates rather than in comparison to a control group of patients. Some studies used a quasi-experimental design but did not provide dialysis modality measures, again limiting full analysis.

Two studies reported rates of "self-care dialysis" but neglected to differentiate between home dialysis (PD or home HD) and self-care HD performed in a satellite unit.

There was only one study presenting a head-to-head comparison of educational programs showing that problemsolving group sessions were instrumental in modality choice. ${ }^{40}$ There were no Cochrane Library systematic reviews that related directly to educational programs for dialysis options. One more-recent Cochrane systematic review ${ }^{62}$ compared studies examining early or late referral to renal units in terms of clinical outcomes including initial dialysis modality. The review did not examine educational programs but did note that studies show early referral results in greater use of PD. The overall better preparation for dialysis in earlyreferred patients probably relates in part to the education delivered at this time, but the evidence review did not allow for that conclusion.

\section{Need for standardization}

Because of the lack of studies comparing detailed components of educational programs, this literature review employed a qualitative rather than quantitative design. The data extraction was conducted with a quasi-systematic method. Keywords and phrases describing content were compared and grouped across studies. However, there is little standardization in the description of intervention (in this case, educational content). For this reason, studies may describe the same content in very different ways or use the same terms to describe very different methods and content. For example, when a program describes a patient's "case worker", they could be referring to an individual who meets with the patients to offer support and counseling, but they could also be referring to the role of a health care professional who manages the patient's interactions between members of the nephrology team (ie, ensuring that the patient is seen 


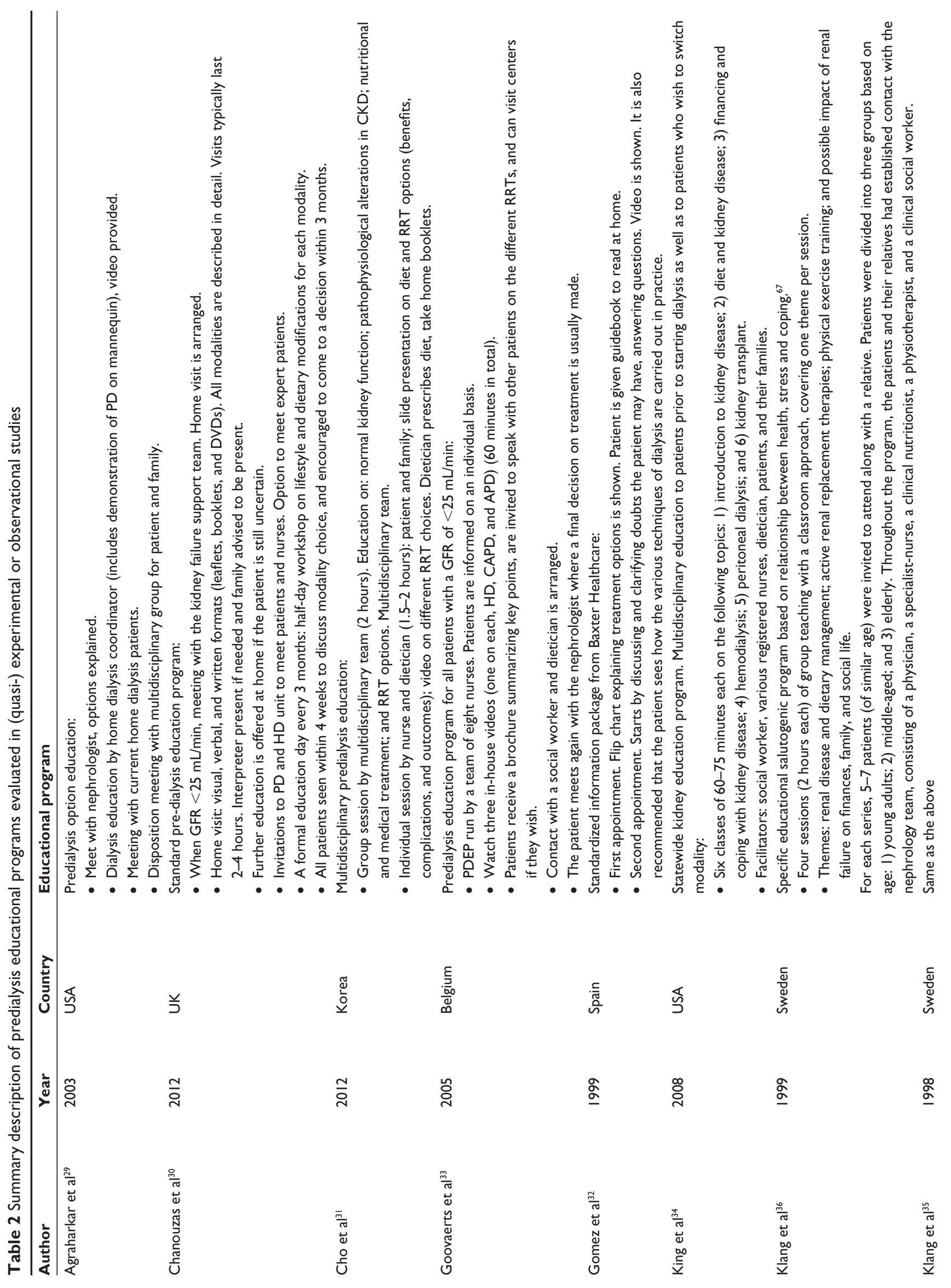




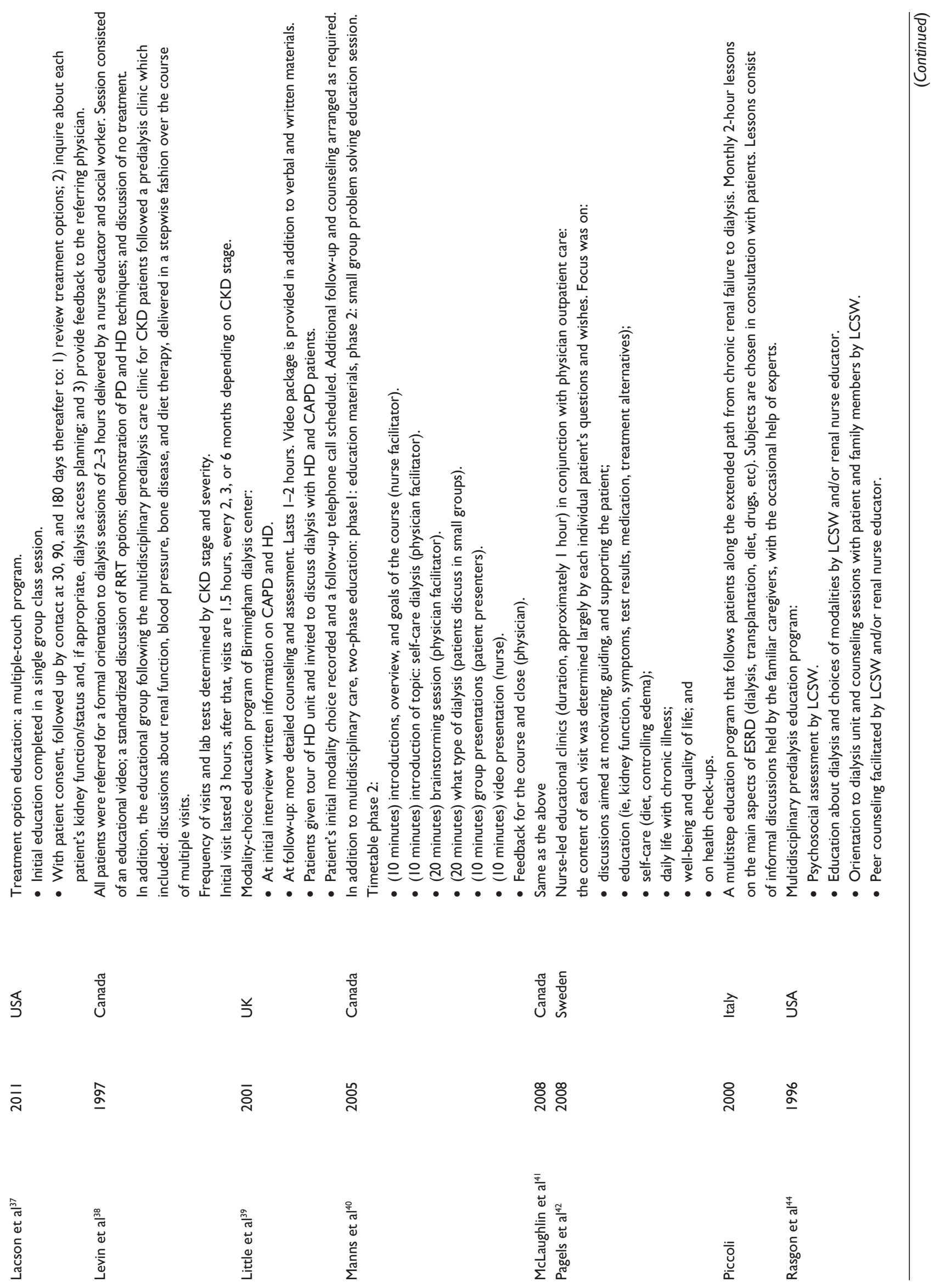




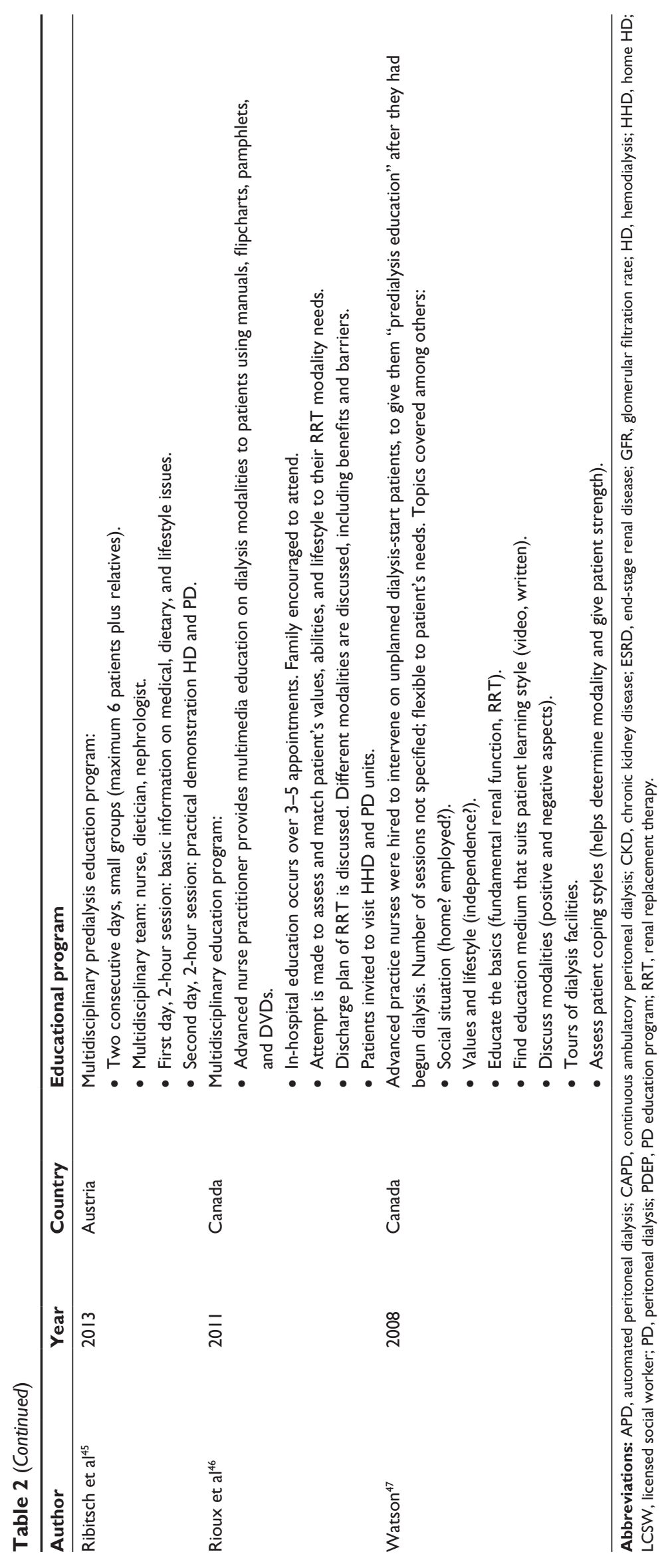


by the nephrologist, arranging appointments with dieticians and social workers as needed), or referring to something else entirely. Likewise, many papers do not use educational theory to describe the selection or design of the educational programs. Much of the creation and description of the educational programs and their content is left to the discretion of the study authors, with no standardized method to describe this across the field.

This lack of standardization of education programs is also acknowledged by professionals in the field of predialysis education. The Provincial PD Joint Initiative in Ontario, Canada, acknowledges that standardized predialysis education supports patients in understanding their options but notes there are no recommendations as to its components or content. ${ }^{22}$

The development of effective interventions is hampered by the absence of a nomenclature to specify and report their content. This limits the possibility of replicating effective interventions, synthesizing evidence, and understanding the causal mechanisms underlying behavior change. In contrast, biomedical interventions are precisely specified (eg, the pharmacological "ingredients" of prescribed drugs, their dose and frequency of administration). For most complex interventions, the precise "ingredients" are unknown; descriptions (eg, "behavioral counseling") can mean different things to different researchers or implementers. The lack of a method for specifying complex interventions undermines the precision of the methodology to review evidence and synthesise its effectiveness, posing a problem for secondary as well as primary research. ${ }^{63}$

The UK Medical Research Council's guidance for developing and evaluating complex interventions acknowledges the need for improved methods of specifying and reporting intervention content. The CONSORT statement for randomized trials of nonpharmacologic interventions calls for precise details of the intervention, including a description of the different intervention components. ${ }^{64}$ For example, this issue of unspecified intervention content is found in other areas of chronic disease, not only renal education programs. For example, researchers have been found to report low confidence in their ability to replicate highly effective interventions for diabetes prevention. ${ }^{63}$

For the development of a taxonomy of education content and regulations for describing this taxonomy to be developed and promoted in the world of renal education, we could learn from other academic fields, such as a taxonomy of behavior change techniques and the use of theory in behavior change intervention design, which are two models that could be expanded and adapted to the field of predialysis education. ${ }^{65,66}$

Educating patients about dialysis options is important to allow informed decision making, but clinical evidence is lacking concerning the most effective educational methods and staff competencies to develop the education. There is a need for a standardized approach built on best evidence from CKD and also from other clinical conditions and existing knowledge on the evaluation of complex interventions to ensure formal evaluation of predialysis education programs, and their effects on clinical outcomes and modality choice.

\section{Acknowledgment}

This work was supported by Baxter Healthcare SA, Zürich, Switzerland.

\section{Disclosure}

Peter A Rutherford was an employee of Baxter Healthcare at the time of performing this research. The authors report no conflicts of interest in this work.

\section{References}

1. Mendelssohn DC, Mujais SK, Soroka SD, et al. A prospective evaluation of renal replacement therapy modality eligibility. Nephrol Dial Transplant. 2009;24:555-561.

2. Heaf JG, Lokkegaard H, Madsen M. Initial survival advantage of peritoneal dialysis relative to haemodialysis. Nephrol Dial Transplant. 2002;17:112-117.

3. Fenton SS, Schaubel DE, Desmeules M, et al. Hemodialysis versus peritoneal dialysis: a comparison of adjusted mortality rates. $\mathrm{Am} \mathrm{J}$ Kidney Dis. 1997;30:334-342.

4. Mehrotra R, Marsh D, Vonesh E, Peters V, Nissenson A. Patient education and access of ESRD patients to renal replacement therapies beyond in-center hemodialysis. Kidney Int. 2005;68:378-390.

5. Covic A, Bammens B, Lobbedez T, et al. Educating end-stage renal disease patients on dialysis modality selection: clinical advice from the European Renal Best Practice (ERBP) Advisory Board. Nephrol Dial Transplant. 2010;25:1757-1759.

6. Ludlow MJ, George CR, Hawley CM, et al. How Australian nephrologists view home dialysis: results of a national survey. Nephrology (Carlton). 2011;16:446-452.

7. Morton RL, Howard K, Webster AC, Snelling P. Patient INformation about Options for Treatment (PINOT): a prospective national study of information given to incident CKD Stage 5 patients. Nephrol Dial Transplant. 2011;26:1266-1274.

8. ERA-EDTA Registry. ERA-EDTA Registry Annual Report 2011. Amsterdam: Academic Medical Center, Department of Medical Informatics: 2013.

9. Gild JRA, Fogarty D. Chapter 1 UK Renal Replacement Therapy Incidence in 2012: UK Renal Registry 16th Annual Report: National and Centre-specific Analyses, 2013. Availale from: https://www.renalreg.org/ wp-content/uploads/2014/09/01-Chap-01.pdf. Accessed 7 Aug 2015.

10. Alberghini E, Gambirasio MC, Sarcina C, et al. [The ambiguous concept of predialysis: proposal for a model]. G Ital Nefrol. 2011;28(5):541-550. Italian.

11. Marrón B, Ocaña JCM, Salgueira M, et al. Analysis of patient flow into dialysis: role of education in choice of dialysis modality. Perit Dial Int. 2005;25 Suppl 3:S56-S59. 
12. Bates M. Improving kidney health and awareness through community based education. Available from: http://www.slideshare.net/Sammy17/ ckd-education. Accessed 7 August 2015.

13. Fortnum D, Mathew T, Johnson K. A model for home dialysis, Australia2012. Kidney Health Australia; 2012. Available from: http://www. kidney.org.au/LinkClick.aspx?fileticket=BfYeuFvtJcI=\&tabid=811\& mid=1886. Accessed 7 August 2015.

14. Glickman J. Chronic Kidney Disease Education. Available from: http://ispd.org/NAC/wp-content/uploads/2010/11/CKD-EducationGlickman-April-2011-Notes.pdf. Accessed 7 August 2015.

15. Pre Dialysis Education [webpage on the Internet]. Charlestown: Hunter Renal Resource Centre; 2012. Available from: http://users.hunterlink. net.au/ mbbjan/pde.html. Accessed 7 August 2015.

16. Wu IW, Wang SY, Hsu KH, et al. Multidisciplinary predialysis education decreases the incidence of dialysis and reduces mortality a controlled cohort study based on the NKF/DOQI guidelines. Nephrol Dial Transplant. 2009;24:3426-3433.

17. Bernardini J, Price V, Figueiredo A. ISPD Guidelines/Recommendations; Peritoneal dialysis patient training, 2006. Perit Dial Int. 2006;26: $625-632$.

18. Roh K, Josland E, Martinez-Smith Y, et al. Renal Department Annual Report and Quality Indicators 2011. Australia: St George Hospital; 2011. Available from: https://stgrenal.org.au/sites/default/files/upload/AnnualReport-2011.pdf. Accessed 7 August 2015.

19. Kidney Healthy Australia. Treatment options-teaching patients (including a summary of "Predialysis Education Survey"). 2012. Available from: http://homedialysis.org.au/health-professional/educating-patients/ treatment-options-teaching-patients/. Accessed 7 August 2015.

20. Kimberly Renal Support Service (KRSS). The Role of Predialysis Coordinator. Available from: http://www.kamsc.org.au/renal/downloads/ renalpresentations/predialysis_role.pdf. Accessed 7 August 2015.

21. Goldstein M, Yassa T, Dacouris N, McFarlane P. Multidisciplinary predialysis care and morbidity and mortality of patients on dialysis. Am J Kidney Dis. 2004;44(4):706-714.

22. Provincial Peritoneal Dialysis Coordinating Committee. Provincial Peritoneal Dialysis Joint Initiative: Resource Manual: Detailed Strategy On Increasing Peritoneal Dialysis (PD) Use In Ontario. Ontario: Provincial Peritoneal Dialysis Coordinating Committee; 2006. Available from: http://www.renalnetwork.on.ca/common/pages/UserFile. aspx?fileId=100547. Accessed 7 August 2015.

23. Walker R, Abel S, Meyer A. What do New Zealand pre-dialysis nurses believe to be effective care? Nurs Prax N Z. 2010;26(2).

24. Crowley ST. CKD Series: Improving the Timing and Quality of Predialysis Care. Wayne: Turner White Communications Inc.; 2003. Available from: http://www.turner-white.com/pdf/hp_aug03_care.pdf. Accessed 7 August 2015.

25. Satellite Healthcare. Satellite WellBound Offers Superior Patient Education Through its Better LIFE ${ }^{\mathrm{TM}}$ Wellness Classes. San Jose: Satellite Healthcare; 2012. Available from: http://www.satellitehealth.com/medical_community/ satellite_wellbound/wellness_classes.php. Accessed 7 August 2015.

26. The Renal Association. RA Guidelines - Planning, Initiating and Withdrawal of Renal Replacement Therapy. UK: 2009. Available from: http://www.renal.org/guidelines/modules/planning-initiatingand-withdrawal-of-renal-replacement-therapy\#sthash.ZpW4QQaN. dpbs. Accessed 7 August 2015.

27. Wilson V, Clarke M. Pre-Dialysis Education and Care - An Important Factor in ESRD Management. Fresenius Medical Care North America; 2004. Available from: http://www.advancedrenaleducation.com/Literature/PDServeConnectionPastArticles/PreESRDANecessity/tabid/347/ Default.aspx. Accessed 7 August 2015.

28. Spijkens YWJ, Berkhout-Byrne NC, Rabelink TJ. Optimal predialysis care. NDT Plus. 2008;1(Suppl 4):iv7-iv13.

29. Agraharkar M, Patlovany M, Henry S, Bonds B. Promoting use of home dialysis. Adv Perit Dial. 2003;19:163-167.

30. Chanouzas D, Ng KP, Fallouh B, Baharani J. What influences patient choice of treatment modality at the pre-dialysis stage? Nephrol Dial Transplant. 2012;27:1542-1547.
31. Cho EJ, Park HC, Yoon HB, et al. Effect of multidisciplinary pre-dialysis education in advanced chronic kidney disease: Propensity score matched cohort analysis. Nephrology (Carlton). 2012;17:472-479.

32. Gómez CG, Valido P, Celadilla O, Bernaldo de Quirós AG, Mojón M. Validity of a standard information protocol provided to end-stage renal disease patients and its effect on treatment selection. Perit Dial Int. 1999; 19:471-477.

33. Goovaerts T, Jadoul M, Goffin E. Influence of a pre-dialysis education programme (PDEP) on the mode of renal replacement therapy. Nephrol Dial Transplant. 2005;20:1842-1847.

34. King K, Witten B, Brown JM, Whitlock RW, Waterman AD. The Missouri Kidney Program's Patient Education Program: a 12-year retrospective analysis. Nephrol News Issues. 2008;22:44-45,48-52, 54.

35. Klang B, Björvell H, Berglund J, Sundstedt C, Clyne N. Predialysis patient education: effects on functioning and well-being in uraemic patients. J Adv Nurs. 1998;28:36-44.

36. Klang B, Björvell H, Clyne N. Predialysis education helps patients choose dialysis modality and increases disease-specific knowledge. J Adv Nurs. 1999;29:869-876.

37. Lacson E Jr, Wang W, DeVries C, et al. Effects of a nationwide predialysis educational program on modality choice, vascular access, and patient outcomes. Am J Kidney Dis. 2011;58:235-242.

38. Levin A, Lewis M, Mortiboy P, et al. Multidisciplinary predialysis programs: quantification and limitations of their impact on patient outcomes in two Canadian settings. Am J Kidney Dis. 1997;29:533-540.

39. Little J, Irwin A, Marshall T, Rayner H, Smith S. Predicting a patient's choice of dialysis modality: experience in a United Kingdom renal department. Am J Kidney Dis. 2001;37:981-986.

40. Manns BJ, Taub K, Vanderstraeten C, et al. The impact of education on chronic kidney disease patients' plans to initiate dialysis with self-care dialysis: a randomized trial. Kidney Int. 2005;68:1777-1783.

41. McLaughlin K, Jones H, Vanderstraeten C, et al. Why do patients choose self-care dialysis? Nephrol Dial Transplant. 2008;23:3972-3976.

42. Pagels AA, Wång M, Wengström Y. The impact of a nurse-led clinic on self-care ability, disease-specific knowledge, and home dialysis modality. Nephrol Nurs J. 2008;35:242-248.

43. Piccoli GB, Mezza E, Iadarola AM, et al. Education as a clinical tool for self-dialysis. Adv Perit Dial. 2000;16:186-190.

44. Rasgon SA, Chemleski BL, Ho S, et al. Benefits of a multidisciplinary predialysis program in maintaining employment among patients on home dialysis. Adv Perit Dial. 1996;12:132-135.

45. Ribitsch W, Haditsch B, Otto R, et al. Effects of a pre-dialysis patient education program on the relative frequencies of dialysis modalities. Perit Dial Int. 2013;33:367-371.

46. Rioux JP, Cheema H, Bargman JM, Watson D, Chan CT. Effect of an in-hospital chronic kidney disease education program among patients with unplanned urgent-start dialysis. Clin J Am Soc Nephrol. 2011;6: 799-804.

47. Watson D. Post-dialysis "pre-dialysis" care: the cart before the horseadvanced practice nurse intervention and impact on modality selection. CANNT J. 2008;18:30-33.

48. Baillod RA. Home dialysis: lessons in patient education. Patient Educ Couns. 1995;26:17-24.

49. Ballerini L, Paris V. Nosogogy: when the learner is a patient with chronic renal failure. Kidney Int Suppl. 2006:S122-S126.

50. Golper T. Patient education: can it maximize the success of therapy? Nephrol Dial Transplant. 2001;16 Suppl 7:20-24.

51. Golper TA, Mehrotra R, Schreiber MS. Is Dorothy correct? The role of patient education in promoting home dialysis. Semin Dial. 2013;26: $138-142$.

52. Keeping LM, English LM. Informal and incidental learning with patients who use continuous ambulatory peritoneal dialysis. Nephrol Nurs J. 2001;28:313-314, 319-322; discussion 323.

53. Kong IL, Yip IL, Mok GW, et al. Setting up a continuous ambulatory peritoneal dialysis training program. Perit Dial Int. 2003;23 Suppl 2: S178-S182. 
54. Lewis AL, Stabler KA, Welch JL. Perceived informational needs, problems, or concerns among patients with stage 4 chronic kidney disease. Nephrol Nurs J. 2010;37:143-148; quiz 149.

55. Luongo M, Kennedy S. Interviewing prospective patients for peritoneal dialysis: a five-step approach. Nephrol Nurs J. 2004;31:513-520.

56. Owen JE, Walker RJ, Edgell L, et al. Implementation of a pre-dialysis clinical pathway for patients with chronic kidney disease. Int J Qual Health Care. 2006;18:145-151.

57. Dixon J, Borden P, Kaneko TM, Schoolwerth AC. Multidisciplinary CKD care enhances outcomes at dialysis initiation. Nephrol Nurs J. 2011; 38:165-171

58. Hall G, Bogan A, Dreis S, et al. New directions in peritoneal dialysis patient training. Nephrol Nurs J. 2004;31:149-154, 159-163.

59. Souqiyyeh MZ, Al-Wakeel J, Al-Harbi A, et al. Effectiveness of a separate training center for peritoneal dialysis patients. Saudi J Kidney Dis Transpl. 2008;19:574-582.

60. Wauters JP, Lameire N, Davison A, Ritz E. Why patients with progressing kidney disease are referred late to the nephrologist: on causes and proposals for improvement. Nephrol Dial Transplant. 2005;20: 490-496.
61. D. F. Pre-dialysis education - A National Australian Survey (Jan 2012). 2012. Available from: http://www.kidney.org.au/LinkClick.aspx?fileticket= 4u5Qky3opAc\%3D\&tabid=635\&mid=1590. Accessed 7 August 2015.

62. Smart NA, Dieberg G, Ladhani M, Titus T. Early referral to specialist nephrology services for preventing the progression to end-stage kidney disease. Cochrane Database Syst Rev. 2014;6:CD007333.

63. Michie S, Abraham C, Eccles MP, Francis JJ, Hardeman W, Johnston M. Strengthening evaluation and implementation by specifying components of behaviour change interventions: a study protocol. Implement Sci. 2011;6:10.

64. Boutron I, Moher D, Altman DG, Schulz KF, Ravaud P; CONSORT Group. Extending the CONSORT statement to randomized trials of nonpharmacologic treatment: explanation and elaboration. Ann Intern Med. 2008;148:295-309.

65. Michie S, Prestwich A. Are interventions theory-based? Development of a theory coding scheme. Health Psychol. 2010;29:1-8.

66. Abraham C, Michie S. A taxonomy of behavior change techniques used in interventions. Health Psychol. 2008;27:379-387.

67. Antonovsky A. The salutogenic model as a theory to guide health promotion. Health Promotional Int. 1996;11(1):11-18.
Patient Preference and Adherence

\section{Publish your work in this journal}

Patient Preference and Adherence is an international, peer-reviewed, open access journal that focuses on the growing importance of patient preference and adherence throughout the therapeutic continuum. Patient satisfaction, acceptability, quality of life, compliance, persistence and their role in developing new therapeutic modalities and compounds to optimize

\section{Dovepress}

clinical outcomes for existing disease states are major areas of interest for the journal. This journal has been accepted for indexing on PubMed Central. The manuscript management system is completely online and includes a very quick and fair peer-review system, which is all easy to use. Visit http://www. dovepress.com/testimonials.php to read real quotes from published authors.

\footnotetext{
Submit your manuscript here: http://www.dovepress.com/patient-preference-and-adherence-journal
} 